\title{
Characterization of Anti Q-fuzzy R-Sub modules over Commutative Rings
}

\author{
R.Nagarajan \\ Assistant Professor \\ Department of Mathematics \\ J.J College of Engg \& Tech \\ Tirchirappalli- 09.
}

\author{
A.Solairaju \\ Associate Professor \\ $\mathrm{Pg} \&$ Research Department Of Mathematics \\ Jamal Mohamed College \\ Tirchirappalli-20.
}

\begin{abstract}
We introduce the concept of anti Q-fuzzy R- sub modules over a commutative ring with respect to $\mathrm{t}$ - norm. Some Properties of anti Q- fuzzy R- sub modules are investigated. In Particular, we consider properties of intersection and direct product for anti Q- fuzzy R- sub modules.
\end{abstract}

Key words: Anti Q-fuzzy R-sub modules, Direct product, T-norm, sensible.

2000 AMS classification: 16Y99, 20N20, 03E72

\section{INTRODUCTION}

The concept of fuzzy set [7] was applied to group theory in [4]. Further, the concept of fuzzy subgroup was generalized to the case where in the definition of an algebraic structure one uses a t- norm [1] instead of the operation min. A significant number of publications are devoted to research of properties of fuzzy Abelian groups ( see, for example, [2] and fuzzy rings [3].The concept of Q- fuzzy submodules was generalized by [6]. In this paper we introduce the concept of anti Q- fuzzy R-sub module and investigate some properties of anti Q- fuzzy R- sub modules. To guarantee a sufficient generality of exposition and account for a variety of various applications, all concepts used here are considered with respect to t-norms.

\section{Preliminaries}

Definition 2.1 : Let $\mu_{\tilde{\mathrm{A}}}: \mathrm{U} \rightarrow[0,1]$ be any function and A be a crisp set in the universe ' $U$ ' then the ordered pairs $\tilde{A}=$ $\left\{\left(\mathrm{x}, \mu_{\tilde{\mathrm{A}}}(\mathrm{x}) / \mathrm{x} \varepsilon \mathrm{U}\right\}\right.$ is called a fuzzy set and $\mu_{\tilde{\mathrm{A}}}$ is called a membership function.

Definition 2.2: By a t- norm ' $\mathrm{T}$ ', we mean a function $\mathrm{T}$ : $[0,1] \times[0,1] \rightarrow[0,1]$ satisfying the following conditions ;
(T1) $\mathrm{T}(0, \mathrm{x})=0$

(T2) $T(x, y) \leq T(x, z)$ if $y \leq z$

(T3) $\mathrm{T}(\mathrm{x}, \mathrm{y})=\mathrm{T}(\mathrm{y}, \mathrm{x})$

(T4) $\mathrm{T}(\mathrm{x}, \mathrm{T}(\mathrm{y}, \mathrm{z}))=\mathrm{T}(\mathrm{T}(\mathrm{x}, \mathrm{y}), \mathrm{z})$, for all $\mathrm{x}, \mathrm{y}, \mathrm{z} \varepsilon[0,1]$.

Proposition 2.3: For a t-norm, then the following statement holds $\mathrm{T}(\mathrm{x}, \mathrm{y}) \leq \min \{\mathrm{x}, \mathrm{y}\}$, for all $\mathrm{x}, \mathrm{y} \varepsilon[0,1]$.

Definition 2.4: Let ' $T$ ' be a t-norm. A fuzzy set ' $A$ ' in ' $R$ ' is said to be sensible with respect to ' $T$ ' if $\operatorname{Im}(\mathrm{A}) \mathrm{c} \Delta \mathrm{T}$, where

$\Delta \mathrm{T}=\{\mathrm{T}(\alpha, \alpha)=\alpha / \alpha \varepsilon[0,1]\}$.

Definition 2.5 : Let $\mathrm{Q}$ and $\mathrm{G}$ be a set and a group respectively. A mapping $\mu: \mathrm{G} \times \mathrm{Q} \rightarrow[0,1]$ is called a $\mathrm{Q}-$ fuzzy set.

Definition 2.6: Let $M$ be a module over a commutative ring $\mathrm{R}$.. A function $\mathrm{A}: \mathrm{M} \times \mathrm{Q} \rightarrow[0,1]$ is called anti $\mathrm{Q}-$ fuzzy R- sub module of ' $M$ ' with respect to s-norm $S$ if and only if for all $\mathrm{x}, \mathrm{y} \varepsilon \mathrm{M}, \mathrm{q} \varepsilon \mathrm{Q}$ and for any $\alpha \varepsilon \mathrm{R}$.

(AFM1) $A(x+y, q) \geq T\{A(x, q), A(y, q)\}$, for all $x, y \in A$.

(AFM2) $\mathrm{A}(\alpha \mathrm{x}, \mathrm{q}) \geq \mathrm{A}(\mathrm{x}, \mathrm{q})$ for all $\alpha, \mathrm{x} \varepsilon \mathrm{R}$.

(AFM3) $\mathrm{A}(0, \mathrm{q})=1$

Definition 2.7 : Define 
$\mathrm{T}_{\mathrm{n}}\left(\left(\mathrm{x}_{1}, \mathrm{x}_{2}, \ldots, \mathrm{x}_{\mathrm{n}}\right), \mathrm{q}\right)=\mathrm{T} \quad\left(\mathrm{x}_{\mathrm{i}}, \quad \mathrm{T}_{\mathrm{n}-1} \quad\left(\left(\mathrm{x}_{1}, \mathrm{x}_{2}, \ldots \mathrm{x}_{\mathrm{i}-1}\right.\right.\right.$, $\left.\left.\mathrm{x}_{\mathrm{i}+1}, \ldots \mathrm{x}_{\mathrm{n}}\right), \mathrm{q}\right)$ ) for all $1 \leq \mathrm{i} \leq \mathrm{n}, \mathrm{n} \geq 2, \mathrm{~T}_{1}=\mathrm{T}$. Also define $\mathrm{T}_{\infty}$ $\left(x_{1}, x_{2}, \ldots, q\right)=\lim T_{n}\left(\left(x_{1}, x_{2}, \ldots, x_{n}\right), q\right)$ as $n \rightarrow \infty$.

Definition 2.8: By the intersection of fuzzy subsets $A_{1}$ and $A_{2}$ in a set $X$ with respect to an t-norm $T$ we mean the fuzzy subset $A=A_{1} \cap A_{2}$ in the set $X$ such that for any $x \varepsilon$ $\mathrm{X} \quad \mathrm{A}(\mathrm{x}, \mathrm{q})=\left(\mathrm{A}_{1} \cap \mathrm{A}_{2}\right)(\mathrm{x}, \mathrm{q})=\mathrm{T}\left(\mathrm{A}_{1}(\mathrm{x}, \mathrm{q}), \mathrm{A}_{2}(\mathrm{x}, \mathrm{q})\right)$. By the intersection of a collection of fuzzy subsets $\left\{A_{1}, A_{2}, \ldots\right\}$ in a set $\mathrm{X}$ with respect to a $\mathrm{t}$ - norm $\mathrm{T}$ we mean the fuzzy subset $\cap A_{i}$ such that for any $x \quad \varepsilon \quad A,\left(\cap A_{i}\right)(x, q)=$ $\mathrm{T}_{\infty}\left\{\mathrm{A}_{1}(\mathrm{x}, \mathrm{q}), \mathrm{A}_{2}(\mathrm{x}, \mathrm{q}), \ldots\right\}$.

Definition 2.9: By the direct product of fuzzy sets \{ $\left.\mathrm{A}_{1}, \mathrm{~A}_{2}, \ldots \ldots.\right\}$ with respect to $\mathrm{t}$ - norm $\mathrm{T}$ we Mean the fuzzy subset $\mathrm{A}\left\{\left(\mathrm{x}_{1}, \mathrm{x}_{2}, \ldots \ldots . . . \mathrm{x}_{\mathrm{n}}\right), \mathrm{q}\right\}$

$=\left(\prod \mathrm{A}_{\mathrm{i}}\right)\left\{\left(\mathrm{x}_{1}, \mathrm{x}_{2}, \ldots \ldots \mathrm{x}_{\mathrm{n}}\right), \mathrm{q}\right\}$

$=T_{n}\left\{A_{1}\left(x_{1}, q\right), A_{2}\left(x_{2}, q\right) \ldots \ldots . . A_{n}\left(x_{n}, q\right)\right\}$

\section{Properties of Anti Q- fuzzy R-sub modules}

Proposition 3.1: If $\mathrm{R}$ is a ring with identity and a t-norm $\mathrm{T}$ for all $\mathrm{x} \quad \varepsilon \quad[0,1]$ satisfies the $\operatorname{condition} \mathrm{T}(\mathrm{x}, \mathrm{x})=\mathrm{x}$. (T5)

Then condition (AFM2) in Definition (2.6) for any $\alpha \varepsilon \mathrm{R}$ is equivalent to the condition

$A(\alpha x, q)=A(x, q)$

$\left(\mathrm{AFM} 2^{1}\right)$

Proof: Let condition (AFM1 ) and (AFM2 ) be fulfilled and 1 be the identity element in the ring $\mathrm{R}$. Then

$A(x, q)=A(\alpha x+(1-\alpha x), q) \geq T(A(\alpha x, q), A(1-\alpha x), q) \geq T$ $A(\alpha x, q), T(A(x, q), A(-\alpha x, q)))) \geq T(A(x, q), T(A(x, q), A(-$ $\alpha \mathrm{x}, \mathrm{q}))$ ). Taking into consideration conditions (T2) and (T5) for the t-norm $\mathrm{T}$ and again applying AFM2), we obtain $\mathrm{T}(\mathrm{A}(\mathrm{x}, \mathrm{q}), \mathrm{T}(\mathrm{A}(\mathrm{x}, \mathrm{q}), \quad \mathrm{A}(-\alpha \mathrm{x}, \mathrm{q})))=\mathrm{T}(\mathrm{T}(\mathrm{A}(\mathrm{x}, \mathrm{q})$, $\mathrm{A}(\mathrm{x}, \mathrm{q}), \mathrm{A}(-\alpha \mathrm{x}, \mathrm{q}))=\mathrm{T}(\mathrm{A}(\mathrm{x}, \mathrm{q}), \mathrm{A}(-\alpha \mathrm{x}, \mathrm{q})) \geq \mathrm{T}(\mathrm{A}(\mathrm{x}, \mathrm{q})$, $\mathrm{A}(\alpha \mathrm{x}, \mathrm{q}))$. Thus we have $\mathrm{A}(\mathrm{x})=\mathrm{T}(\mathrm{A}(\mathrm{x}, \mathrm{q}), \mathrm{A}(\mathrm{x}, \mathrm{q})) \geq \mathrm{T}$ $(A(x, q), A(\alpha x, q))$.From here, using condition (T4), we conclude that $A(x, q) \geq A(\alpha x, q)$

(1) From

(1) and condition (AFM2) we obtain $\left(\mathrm{AFM} 2^{1}\right)$.
Proposition 3.2 : If $\mathrm{R}$ is a field, then condition ( AFM2 ) in Definition 2.6 for any $\alpha \varepsilon \mathrm{R}, \alpha \neq 0$, is equivalent to condition $\left(\mathrm{AFM} 2^{1}\right)$.

Proof: Let the condition (AFM2) be satisfied. If $\alpha \neq 0$, then applying (AFM2) we obtain $\mathrm{A}(\alpha \mathrm{x}, \mathrm{q}) \geq \mathrm{A}(\mathrm{x}, \mathrm{q})=\mathrm{A}(1 / \alpha$ $(\alpha x, q)) \geq A(\alpha x, q)$. From here it follows that $A(\alpha x, q)=$ $\mathrm{A}(\mathrm{x}, \mathrm{q})$, i.e., condition $\left(\mathrm{AFM} 2^{1}\right)$ is satisfied.

Proposition 3.3: If a fuzzy set $A$ is normal, then condition(AFM3) in Definition 2.6 follows from conditions (AFM1) and (AFM2).

Proof: Let, for a fuzzy set A, condition (AFM1) and (AFM2) be fulfilled. Since the fuzzy set A is normal, there exists $x \in M$ such that (1) is fulfilled. Then, for such $x$, applying conditions (AFM1) and (AFM2), we obtain $\mathrm{A}(0, \mathrm{q})=\mathrm{A}(\mathrm{x}-\mathrm{x}, \mathrm{q}) \geq \mathrm{T}(\mathrm{A}(\mathrm{x}, \mathrm{q}), \mathrm{A}(-\mathrm{x}, \mathrm{q}))=\mathrm{T}(1, \mathrm{~A}(-\mathrm{x}, \mathrm{q})=$ $A(-x, q) \geq A(x, q)=1$. From here it follows that $A(0, q)=$ 1. Thus, condition $\left(\mathrm{AFM} 2^{1}\right)$ is satisfied.

Proposition 3.4 : If A is anti Q- fuzzy R- sub module of M with respect to a t- norm $\mathrm{T}$, then $\mathrm{M}_{1}=\{\mathrm{x} / \mathrm{x} \varepsilon \mathrm{M}, \mathrm{A}(\mathrm{x}, \mathrm{q})=$ $0\}$ is a sub module of the module M and A is anti Q-fuzzy $\mathrm{R}$ - sub module of $\mathrm{M}_{1}$, with respect to the $\mathrm{t}$ - norm $\mathrm{T}$.

Proof: Let $\mathrm{x}, \mathrm{y} \varepsilon \mathrm{M}_{1}$ and $\alpha \varepsilon \mathrm{R}$. Then, according to condition ( AFM2 $), A(x+y, q) \geq T(A(x, q), A(y, q))=T(1,1)$ $=1$. Thus,$A(x+y, q)=1$. Hence $x+y \in M_{1}$. According to condition (AFM1), $\mathrm{A}(\alpha \mathrm{x}, \mathrm{q}) \geq \mathrm{A}(\mathrm{x}, \mathrm{q})=1$. Thus, we have $\mathrm{A}(\alpha \mathrm{x}, \mathrm{q})=1$. From here it follows that $\alpha \mathrm{x} \varepsilon \mathrm{M}_{1}$. Finally, according to condition (AFM3), $\mathrm{A}(0, \mathrm{q})=1$. Therefore, 0 $\varepsilon \mathrm{M}_{1}$. Thus $\mathrm{M}_{1}$ is a sub module of module $\mathrm{M}$.

The second part of the statement of proposition 3.4 is obvious.

Proposition 3.5; If , for a unitary $\operatorname{ring} \mathrm{R}, \mathrm{A}$ is a anti Qfuzzy R-sub module of $\mathrm{M}$ with respect to a t-norm $\mathrm{T}$, then $\mathrm{A}$ is a anti Q- fuzzy subgroup of $\mathrm{M}$ with respect to $\mathrm{T}$.

Proof: Let $x \in A$. Then $\quad A(-x, q)=A((-1 . x), q) \geq A(x, q)$. Thus, A is anti Q- fuzzy module of $\mathrm{M}$ with respect to the $\mathrm{t}$ norm $\mathrm{T}$. 
Proposition3.6: Let ' $\mathrm{T}$ ' be a t-norm. Then every sensible anti Q- fuzzy R-modules 'A' of R is anti Q- fuzzy R- sub modules of $\mathrm{R}$.

Proof: Assume that 'A' is a sensible anti Q- fuzzy R-sub modules of $\mathrm{R}$, then we have (AFM1) $\mathrm{A}(\mathrm{x}+\mathrm{y}, \mathrm{q}) \geq \mathrm{T}(\mathrm{A}(\mathrm{x}, \mathrm{q})$, $A(y, q))$ and $(A F M 2) A(\alpha x, q) \geq A(x, q)$ for all $x, y \& R$.

Since ' $A$ ' is sensible, we have

$\operatorname{Min}\{\mathrm{A}(\mathrm{x}, \mathrm{q}), \mathrm{A}(\mathrm{y}, \mathrm{q})\}=\mathrm{T}(\min \{\mathrm{A}(\mathrm{x}, \mathrm{q}), \mathrm{A}(\mathrm{y}, \mathrm{q}), \min \{$ $\mathrm{A}(\mathrm{x}, \mathrm{q}), \mathrm{A}(\mathrm{y}, \mathrm{q})\}$

$\geq \mathrm{T}\{\mathrm{A}(\mathrm{x}, \mathrm{q}), \mathrm{A}(\mathrm{y}, \mathrm{q})\}$

$\geq \min \{\mathrm{A}(\mathrm{x}, \mathrm{q}), \mathrm{A}(\mathrm{y}, \mathrm{q})\}$

and so $\mathrm{T}(\mathrm{A}(\mathrm{x}, \mathrm{q}), \mathrm{A}(\mathrm{y}, \mathrm{q})\}=\min \{\mathrm{A}(\mathrm{x}, \mathrm{q}), \mathrm{A}(\mathrm{y}, \mathrm{q})\}$. It follows that

$\mathrm{A}(\mathrm{x}+\mathrm{y}, \mathrm{q}) \geq \mathrm{T}(\mathrm{A}(\mathrm{x}, \mathrm{q}), \mathrm{A}(\mathrm{y}, \mathrm{q})\}$

$=\min \{\mathrm{A}(\mathrm{x}, \mathrm{q}), \mathrm{A}(\mathrm{y}, \mathrm{q})\}$ for all $\mathrm{x}, \mathrm{y}$ in $\mathrm{R}$.

Clearly $A(\alpha x, q) \geq A(x, q)$ for all $r, x$ in $R$. So 'A' is an anti Q-fuzzy R-sub modules of R.

Proposition 3.7: If $\mathrm{A}$ is anti Q-fuzzy R-sub module of $\mathrm{M}$ with respect to the t-norm min, then for any $\theta \varepsilon[0,1], \mathrm{M}_{\theta}$ $=\{\mathrm{x} / \mathrm{x} \varepsilon \mathrm{M}, \mathrm{A}(\mathrm{x}, \mathrm{q}) \geq \theta\}$ is a sub module of the module $\mathrm{M}$ and $\mathrm{A}$ is anti Q-fuzzy $\mathrm{R}$ - sub module of $\mathrm{M}_{\theta}$ with respect to to $\min$.

Proof; Let $\mathrm{x}, \mathrm{y} \varepsilon \mathrm{M}_{1}$, and $\alpha \varepsilon \mathrm{R}$, Then $\mathrm{A}(\mathrm{x}+\mathrm{y}, \mathrm{q}) \geq \min \{$ $\mathrm{A}(\mathrm{x}, \mathrm{q}), \mathrm{A}(\mathrm{y}, \mathrm{q})\}=\min \{\theta, \theta\}=\theta$. Thus $\mathrm{A}(\mathrm{x}+\mathrm{y}, \mathrm{q}) \geq \theta$. Hence $\mathrm{x}+\mathrm{y} \& \mathrm{M}_{\theta}$. Further, we have $\mathrm{A}(\alpha \mathrm{x}, \mathrm{q}) \geq \mathrm{A}(\mathrm{x}, \mathrm{q}) \geq \theta$. From here we conclude that $\alpha \mathrm{x} \varepsilon \mathrm{M}_{\theta}$. Finally, from $\mathrm{A}(0, \mathrm{q})=1 \geq \theta$ it follows that $0 \& \mathrm{M}_{\theta}$.

Proposition 3.8: Let $\mathrm{A}: \mathrm{B} \rightarrow[0,1]$ be the characteristic function of a subset $\mathrm{B}$ is contained in $\mathrm{M}$ and $\mathrm{M}$ be an $\mathrm{R}$ module. Then A is anti Q- fuzzy R-sub module of M with respect to $\mathrm{t}$-norm $\mathrm{T}$ if and only if $\mathrm{B}$ is a sub module of the module $\mathrm{M}$.
Proof: Let A be anti Q-fuzzy R- sub module of $\mathrm{M}$ with respect to $\mathrm{T}$. Then, according to (AFM2), $\mathrm{A}(\alpha \mathrm{x}, \mathrm{q}) \geq \mathrm{A}(\mathrm{x}, \mathrm{q})$ $=1$. Hence $\alpha \mathrm{x} \varepsilon$ B. Finally, according to condition (AFM3), $A(0, q)=1$. Therefore, $0 \varepsilon$ B.Thus, B is a sub module of the module $\mathrm{M}$

Conversely, Let B be a sub module of the module $\mathrm{M}$. Then for any $\mathrm{x}, \mathrm{y} \varepsilon \mathrm{M}$,

$$
A(x+y, q) \geq T(A(x, q), A(y, q)\} .
$$

Indeed, for any $\mathrm{x}, \mathrm{y} \varepsilon \mathrm{B}$,

$\mathrm{A}(\mathrm{x}+\mathrm{y}, \mathrm{q})=1 \geq 1=\mathrm{T}(1,1)=\mathrm{T}(\mathrm{A}(\mathrm{x}, \mathrm{q}), \mathrm{A}(\mathrm{y}, \mathrm{q})\}$

For any $\mathrm{x} \varepsilon \mathrm{B}$, and $\mathrm{y}$ is not in $\mathrm{B}, \mathrm{T}(\mathrm{A}(\mathrm{x}, \mathrm{q}), \mathrm{A}(\mathrm{y}, \mathrm{q}))=\mathrm{T}(1.0)$ $=0 \geq \mathrm{A}(\mathrm{x}+\mathrm{y}, \mathrm{q})$

For any $\mathrm{x}$ is not in $\mathrm{B}$, and $\mathrm{y} \varepsilon \mathrm{B}, \mathrm{T}(\mathrm{A}(\mathrm{x}, \mathrm{q}), \mathrm{A}(\mathrm{y}, \mathrm{q}))=\mathrm{T}(0,1)$ $=0 \geq A(x+y, q)$

Finally, for any $\mathrm{x}, \mathrm{y}$ does not belong to $\mathrm{B}, \mathrm{T}(\mathrm{A}(\mathrm{x}, \mathrm{q}), \mathrm{A}(\mathrm{y}, \mathrm{q}))$ $=\mathrm{T}(0,0)=0 \geq \mathrm{A}(\mathrm{x}+\mathrm{y}, \mathrm{q})$

Further for all $\mathrm{x} \varepsilon \mathrm{M}$, and $\alpha \varepsilon \mathrm{R}$, we have $\mathrm{A}(\alpha \mathrm{x}, \mathrm{q}) \geq \mathrm{A}(\mathrm{x})$. Indeed, for all $\mathrm{x} \varepsilon \mathrm{B}$ we have $\alpha \mathrm{x} \varepsilon \mathrm{B}$, hence $\mathrm{A}(\alpha \mathrm{x}, \mathrm{q})=1 \geq$ $\mathrm{A}(\mathrm{x}, \mathrm{q})$, and for all $\mathrm{x}$ does not belong to $\mathrm{B}$ we have $\mathrm{A}(\mathrm{x}, \mathrm{q})=$ $0 \leq \mathrm{A}(\alpha \mathrm{x}, \mathrm{q})$.

Finally, since $0 \varepsilon B$, we have $A(0, q)=1$. Therefore, $A$ is anti Q-fuzzy R-sub module of $\mathrm{M}$ with respect to $\mathrm{T}$.

Proposition 3.9; The intersection of any collection of anti Q- fuzzy R- sub modules of an R-module $\mathrm{M}$ is anti Qfuzzy sub module of this module.

Proof: For all $\mathrm{x}, \mathrm{y} \varepsilon \mathrm{M}$, and any $\alpha \varepsilon \mathrm{R}$, we have

$\cap A_{i} \quad(x+y, q)=T_{\infty}\left(A_{1}(x+y, q), \quad A_{2}(x+y, q), \quad \ldots\right) \geq$ $\mathrm{T}_{\infty}\left(\mathrm{T}_{\infty}\left(\mathrm{A}_{1}(\mathrm{x}, \mathrm{q}), \mathrm{A}_{1}(\mathrm{y}, \mathrm{q})\right), \mathrm{T}_{\infty}\left(\mathrm{A}_{2}(\mathrm{x}, \mathrm{q}), \mathrm{A}_{2}(\mathrm{y}, \mathrm{q})\right), \ldots\right)$

$=\mathrm{T}_{\infty}\left(\mathrm{T}_{\infty}\left(\mathrm{A}_{1}(\mathrm{x}, \mathrm{q}), \mathrm{A}_{2}(\mathrm{x}, \mathrm{q}),, \ldots\right), \mathrm{T}_{\infty}\left(\mathrm{A}_{1}(\mathrm{y}, \mathrm{q}), \mathrm{A}_{2}(\mathrm{y}, \mathrm{q}), \ldots\right)\right)$

$=\mathrm{T}_{\infty}\left(\left(\cap \mathrm{A}_{\mathrm{i}}\right)(\mathrm{x}, \mathrm{q}),\left(\cap \mathrm{A}_{\mathrm{i}}\right)(\mathrm{y}, \mathrm{q})\right)$;

$\left.\left(\cap A_{i}\right)(\alpha x, q)=T_{\infty} A_{1}(\alpha x, q), A_{2}(\alpha x, q),, \ldots\right) \geq T_{\infty}\left(A_{1}(x, q)\right.$,

$\left.A_{2}(x, q), \ldots\right)=\left(\cap A_{i}\right)(x, q)$; 
$\left(\cap A_{i}\right)(0, q)=T_{\infty}\left(A_{1}(0, q), A_{2}(0, q), \ldots\right) \quad=T_{\infty}(1,1, \ldots)=$

1.

Proposition is proved.

Proposition 3.10: If ' $A$ ' is a anti Q- fuzzy R-sub modules of a commutative ring $\mathrm{R}$ and ' $\theta$ ' is an endomorphism of $\mathrm{R}$, then $A_{[\theta]}$ is anti Q-fuzzy $R$ - sub modules of $R$.

Proof: for any $\mathrm{x}, \mathrm{y} \varepsilon \mathrm{R}$, we have

(i) $\mathrm{A}_{[\theta]}(\mathrm{x}+\mathrm{y}, \mathrm{q})=\mathrm{A}(\theta(\mathrm{x}+\mathrm{y}, \mathrm{q})$

$$
\begin{aligned}
& =\mathrm{A}(\theta(\mathrm{x}, \mathrm{q})+\theta(\mathrm{y}, \mathrm{q})) \\
& \geq \mathrm{T}\left(\mathrm{A}_{[\theta]}(\mathrm{x}, \mathrm{q}), \mathrm{A}_{[\theta]}(\mathrm{y}, \mathrm{q})\right)
\end{aligned}
$$

(ii) $\mathrm{A}_{[\theta]}(\alpha \mathrm{x}, \mathrm{q})=\mathrm{A}(\theta(\alpha \mathrm{x}, \mathrm{q}))$

$$
\begin{aligned}
& =A(\alpha \theta(x, q)) \\
& \geq A(\theta(x, q)) \\
& \geq A_{[\theta]}(x, q), \text { hence } A_{[\theta]} \text { is anti Q-fuzzy }
\end{aligned}
$$

$\mathrm{R}$-sub modules of $\mathrm{R}$.

Proposition 3.11: Let $\left\{\mathrm{M}_{1}, \mathrm{M}_{2}, \ldots, \mathrm{M}_{\mathrm{n}}\right\}$ be a collection of R-modules and $\mathrm{M}=\prod \mathrm{A}_{\mathrm{i}}$ be its direct product. Let $\left\{\mathrm{A}_{1}, \mathrm{~A}_{2}, \ldots, \mathrm{A}_{\mathrm{n}}\right\}$ be anti Q-fuzzy sub modules of the Rmodules $\left\{\mathrm{M}_{1}, \mathrm{M}_{2}, \ldots, \mathrm{M}_{\mathrm{n}}\right\}$ with respect to a t-norm T.Then $\mathrm{A}=\prod \mathrm{A}_{\mathrm{i}}$ is anti $\mathrm{Q}$ - fuzzy sub module of the $\mathrm{R}$ - module $\mathrm{M}$ with respect to the $\mathrm{t}$-norm $\mathrm{T}$.

Proof: Let $\mathrm{x}, \mathrm{y} \varepsilon \mathrm{M}, \mathrm{x}=\left(\mathrm{x}_{1}, \mathrm{x}_{2}, \ldots \mathrm{x}_{\mathrm{n}}\right)$, and $\quad \mathrm{y}=$ $\left(\mathrm{y}_{1}, \mathrm{y}_{2}, \ldots \mathrm{y}_{\mathrm{n}}\right)$. Also let $\alpha \varepsilon$ R.Then

$\mathrm{A}(\mathrm{x}+\mathrm{y}, \mathrm{q})=\mathrm{A} \quad\left(\left(\mathrm{x}_{1}+\mathrm{y}_{1}, \mathrm{x}_{2}+\mathrm{y}_{2}, \quad \ldots, \mathrm{x}_{\mathrm{n}}+\mathrm{y}_{\mathrm{n}}\right), \mathrm{q}\right)=$ $\mathrm{T}_{\mathrm{n}}\left(\mathrm{A}_{1}\left(\left(\mathrm{x}_{1}+\mathrm{y}_{1}\right), \mathrm{q}\right), \mathrm{A}_{2}\left(\left(\mathrm{x}_{2}+\mathrm{y}_{2}\right), \mathrm{q}\right), \ldots, \mathrm{A}_{\mathrm{n}}\left(\left(\mathrm{x}_{\mathrm{n}}+\mathrm{y}_{\mathrm{n}}\right), \mathrm{q}\right)\right)$

$\geq T_{n}\left(T\left(A_{1}\left(x_{1}, q\right), A_{1}\left(y_{1}, q\right)\right), T\left(A_{2}\left(x_{2}, q\right), A_{2}\left(y_{2}, q\right)\right), \ldots\right.$, $\left.\mathrm{T}\left(\mathrm{A}_{\mathrm{n}}\left(\mathrm{x}_{\mathrm{n}}, \mathrm{q}\right), \mathrm{A}_{\mathrm{n}}\left(\mathrm{y}_{\mathrm{n}}, \mathrm{q}\right)\right)\right)$

$=\mathrm{T}\left(\mathrm{T}_{\mathrm{n}}\left(\mathrm{A}_{1}\left(\mathrm{x}_{1}, \mathrm{q}\right), \quad \mathrm{A}_{2}\left(\mathrm{x}_{2}, \mathrm{q}\right), \ldots \mathrm{A}_{\mathrm{n}}\left(\mathrm{x}_{\mathrm{n}}, \mathrm{q}\right)\right), \quad \mathrm{T}_{\mathrm{n}}\left(\mathrm{A}_{1}\left(\mathrm{y}_{1}, \mathrm{q}\right)\right.\right.$, $\left.\left.\mathrm{A}_{2}\left(\mathrm{y}_{2}, \mathrm{q}\right), \ldots, \mathrm{A}\left(\mathrm{y}_{\mathrm{n}}, \mathrm{q}\right)\right)\right)$

$=\mathrm{T}(\mathrm{A}(\mathrm{x}, \mathrm{q}), \mathrm{A}(\mathrm{y}, \mathrm{q})), \mathrm{A}(\alpha \mathrm{x}, \mathrm{q})$

$=\mathrm{A}\left(\left(\alpha \mathrm{x}_{1}, \alpha \mathrm{x}_{2}, \ldots, \alpha \mathrm{x}_{\mathrm{n}}\right), \mathrm{q}\right)$
$=T_{n}\left(A_{1}\left(\alpha x_{1}, q\right), A_{2}\left(\alpha x_{2}, q\right), \ldots, A_{n}\left(\alpha x_{n}, q\right)\right)$

$\geq T_{n}\left(A_{1}\left(x_{1}, q\right), A_{2}\left(x_{2}, q\right), \ldots A_{n}\left(x_{n}, q\right)\right)$,

$A(0, q)=A\left(\left(0_{1}, 0_{2}, \ldots, 0_{n}\right), q\right)$

$=T_{n}\left(\left(A_{1}\left(0_{1}, q\right), A_{2}\left(0_{2}, q\right), \ldots, A_{n}\left(0_{n}, q\right)\right)\right.$

$=\mathrm{T}_{\mathrm{n}}(1,1, \ldots, 1)=1$. Therefore, $\mathrm{A}$ is anti Q-fuzzy $\mathrm{R}$ - sub module of the module $\mathrm{M}$ with respect to $\mathrm{T}$.

Proposition 3.12: An onto homomorphic image of anti Q-fuzzy R-sub modules with sup property is anti Qfuzzy R-sub modules.

Proof: Let $\mathrm{f}: \mathrm{R} \rightarrow \mathrm{R}^{1}$ be an onto homomorphism of a ring and let 'A' be anti Q- fuzzy R-sub modules of R with sup property. Given $\mathrm{x}, \mathrm{y} \varepsilon \mathrm{R}$, we let $\mathrm{x}_{\mathrm{o}} \varepsilon \mathrm{f}^{1}\left(\mathrm{x}^{1}\right)$, and $\mathrm{y}_{\mathrm{o}} \varepsilon \mathrm{f}^{1}\left(\mathrm{y}^{1}\right)$ be such that

$$
\begin{array}{ll}
\mathrm{A}\left(\mathrm{x}_{0}, \mathrm{q}\right)=\quad & \sup \mathrm{A}(\mathrm{h}, \mathrm{q}), \\
\mathrm{h} \varepsilon \mathrm{f}^{-1}\left(\mathrm{x}^{1}\right) & \\
\mathrm{A}\left(\mathrm{y}_{\mathrm{o}}, \mathrm{q}\right)=\quad & \sup \mathrm{A}(\mathrm{h}, \mathrm{q}) \\
& \mathrm{h} \varepsilon \mathrm{f}^{1}\left(\mathrm{y}^{1}\right) \text { Respectively. Then we can }
\end{array}
$$

deduce that

$A^{f}\left(x^{1}-y^{1}, q\right)=\sup \quad A(z, q)$

$$
\mathrm{z} \in \mathrm{f}^{-1}\left(\mathrm{x}^{1}-\mathrm{y}^{1}\right)
$$

$$
\begin{aligned}
& \leq \min \left\{A\left(x_{0}, q\right), A\left(y_{0}, q\right)\right\} \\
& =\min \{\sup A(h, q), \quad \sup A(h, q)\} \\
& \qquad \mathrm{h}^{-1}\left(x^{1}\right) \quad h \varepsilon f^{-1}\left(y^{1}\right) \\
& =\min \left\{A^{f}\left(x^{1}, q\right), A^{f}\left(y^{1}, q\right)\right\}
\end{aligned}
$$

$$
\begin{aligned}
\mathrm{A}^{\mathrm{f}}(\alpha \mathrm{x}, \mathrm{q})= & \sup \mathrm{A}(\mathrm{z}, \mathrm{q}) \leq \mathrm{A}\left(\mathrm{y}_{\mathrm{o}}, \mathrm{q}\right) \\
& \mathrm{z} \in \mathrm{f}^{-1}\left(\alpha^{1} \mathrm{x}^{1}\right) \\
= & \sup \mathrm{A}(\mathrm{h}, \mathrm{q})=\mathrm{A}^{\mathrm{f}}\left(\mathrm{y}^{1}, \mathrm{q}\right) \\
& \mathrm{h} \varepsilon \mathrm{f}^{-1}\left(\mathrm{y}^{1}\right)
\end{aligned}
$$


Hence $\mathrm{A}^{\mathrm{f}}$ is anti Q- fuzzy R-sub modules of R.

Conclusion:AbuOsman[1] introduced the concept of Direct product of fuzzy subgroups.[6] investigated the concept of lattice valued Q- fuzzy sub modules of near rings. In this paper we investigate the concept of Anti Qfuzzy right $\mathrm{R}$ - sub modules over commutative rings and derive some simple consequences.

Applications: This work has enormous applicability in the diverse disciplines of biosciences (such as bisocosmology, bisoseismology, bis-behavioural sciences and neural networks.

Acknowledgement: The authors are highly thankful to the referees for their valuable comments and suggestions for improving the paper. This research work fully supported by J.J.EDUCATIONAL HEALTH \& CHARITABLE TRUST, Tiruchirappalli.

\section{REFERENCES}

1.M.T.Abu Osman, " On the direct product of fuzzy subgroups" Fuzzy sets and systems, 12,87-91(1984).

2.T.Lu and W.Gu, " Abelian Fuzzy group and its properties", Fuzzy sets and systems, 64, 415-420(1993).

3.D.S.Malik and J.N.Mordeson, " Fuzzy direct sums of fuzzy rings", Fuzzy sets and systems,45,83-91(1992)

4.A.Rosenfeld, “ Fuzzy groups”, J.Math.Anal.Appl.35,512517(1971)

5.A.Solairaju and R.Nagarajan, A New Structure and Constructions of $Q$ - Fuzzy groups, Advances in Fuzzy mathematics, 4(1)(2009), 23-29.

6.A.Solairaju and R.Nagarajan, Lattice valued $Q$ - fuzzy sub modules of near rings with respect to To norms, Advances in Fuzzy mathematics, 4(2)(2009),137-145.

7.L.A.Zadeh, “ Fuzzy sets”, Inform.Control, 8,338353(1965). 